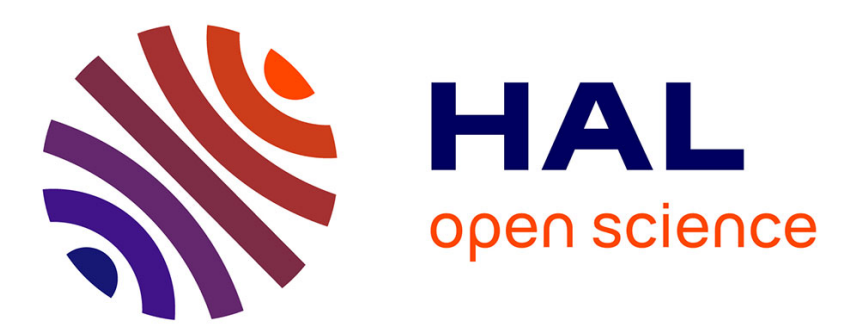

\title{
Magnetic and dielectric properties of carbon nanotubes with embedded cobalt nanoparticles
}

Andrey S. Andreev, ariya A. Kazakova, Arcady V. Ishchenko, Alexander G. Selyutin, Olga B. Lapina, Vladimir L. Kuznetsov, Jean-Baptiste D'espinose de Lacaillerie

\section{- To cite this version:}

Andrey S. Andreev, ariya A. Kazakova, Arcady V. Ishchenko, Alexander G. Selyutin, Olga B. Lapina, et al.. Magnetic and dielectric properties of carbon nanotubes with embedded cobalt nanoparticles. Carbon, 2017, 114, pp.39 - 49. 10.1016/j.carbon.2016.11.070 . hal-01418335

\section{HAL Id: hal-01418335 https://hal.science/hal-01418335}

Submitted on 16 Dec 2016

HAL is a multi-disciplinary open access archive for the deposit and dissemination of scientific research documents, whether they are published or not. The documents may come from teaching and research institutions in France or abroad, or from public or private research centers.
L'archive ouverte pluridisciplinaire HAL, est destinée au dépôt et à la diffusion de documents scientifiques de niveau recherche, publiés ou non, émanant des établissements d'enseignement et de recherche français ou étrangers, des laboratoires publics ou privés. 


\title{
Magnetic and dielectric properties of carbon nanotubes with embedded cobalt nanoparticles
}

\author{
Andrey S. Andreev ${ }^{\text {a, b, c }}$, Mariya A. Kazakova ${ }^{\text {a, b }}$, Arcady V. Ishchenko ${ }^{\text {a, b }}$, \\ Alexander G. Selyutin ${ }^{\mathrm{a}}$, Olga B. Lapina ${ }^{\mathrm{a}, \mathrm{b}}$, Vladimir L. Kuznetsov ${ }^{\mathrm{a}, \mathrm{b}}$, \\ Jean-Baptiste d'Espinose de Lacaillerie
}

"Bareskov institute of Catzlysis, SB RAS Levrentiova S, Novosibirsk 630090, Rascig

b Novosibirsk Stut University. Pirogova 2, Novosihirsk, 620090, Russia

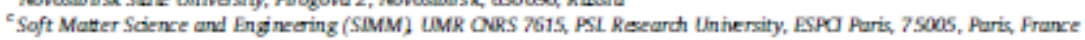

\section{A R T I C L E I N F O}

\section{Avtide histary:}

Received 7 July 2016

Received in revised form

22 Novernber 2016

Acrepted 26 November 2016

Avail able on line 28 November 2016
A B STR ACT

Obtaining stable metal nanoparticles is of high interest for various applications such as catalysis, batteries, supercapacitors and electro-magnetic devices, Cobalt/multi-walled carbon nanotubes (MWCNT) hybrids with an original set of magnetic and electric properties were formed by casting Co nanoparticles $(3-5 \mathrm{~nm})$ of high aspect ratios within the intemal space of MWCNTs. The Co particles localization and size were analyzed by transmission electron microscopy and synchrotron $\mathrm{x}$-ray diffraction. The magnetism of the cobalt nanoparticles was probed by ${ }^{90} \mathrm{Co}$ intemal field nuclear magnetic resonance (IF NMR) and their electrical behavior by dielectric spectroscopy. The majority of Co particles were fully metallic. They resisted sintering up to $550^{\circ} \mathrm{C}$ Below $7.5 \mathrm{wt}$, the Co was exclusively embedded inside the MWCNT. At higher bading, they coexisted with larger Co outside particles. While nanometer size particles are normally superparamagnetic at room temperature, the confinement of Co within MWCNTs resulted in a ferromagnetism revealed by ${ }^{90}$ Co IF NMR. This spectroscopy provided original information about the structure, size, and shape a nisotropy of the nanoparticles Finally, the MWCNT modification by Co metal nanoparticles improved the electrical conductivity of polyethylene based composite thus extending the useful frequency band of Co/MWCNT/PE composites for applications requiring lightweight conduction or energy absorption. 
with a large diversity of tunable elextro-magnetic properties. Finally, the steric control exerted by the well-defined tubular geometry of ONT at the nanoscale opens the possibility to stabilize magnetic NPs of original shapes and structures [28]. This in particular, is a key to control the performance of ternary composites such magnetic NPs/CNT/polymers, a material of tremendous potential for electro-magnetic shielding [29-31].

A common synthetic route to produce Co/CNT composites and hybrids is incipient wetness impregnation with cobalt salt solutions $[7,8]$. This technique is most simple and easily up scaled. Nevertheless, some more exotic techniques also have been explored $[32,33]$, with specific advantages such as the solvothermal method which can reach Co loadings up to 60 wt\% $[28,34]$. The majority of studies have so far been performed on multi-wall QNT of average diameter in the $50-70 \mathrm{~nm}$ range [35]. However, multi-wall aNT of smaller diameter are in some cases of higher interest because they exhibit larger surface areas and much larger elastic moduli [36]. Furthermore, smaller tube diameters offer the potential to cast particles of even smaller sizes. An important step of hybrid preparation is the necessity of opening up the CNT to fill their internal space with the Co phase. This can be achieved by treatment with concentrated nitric acid, with the added benefit of creating anchoring sites for $\mathrm{Co}$ on the CNTs surface $[37,38]$.

Whatever the chosen synthetic route, the Co precursors loaded on, or in, the CNT (thus forming a true hybrid structure) must be reduced to its metallic state. This is most commonly achieved by exposure to a hydrogen gas flow at elevated temperatures. This reduction procedure is known to proceed in two steps as the spinel $\mathrm{CO}_{3} \mathrm{O}_{4}$ phase, $\mathrm{Co}$ (II) and $\mathrm{Co}(\mathrm{III})$, stable under atmospheric conditions, is first reduced into $\mathrm{CoO}, \mathrm{Co}(\mathrm{II})$, and then into $\mathrm{Co}(0)$ metal $[39,40]$. Since the reverse oxidation reaction occurs easily even at room temperature and is auto-catalytic and pyrophoric in NPs, the Co metal surface is usually passivated by creating a thin oxidized layer through a final treatment with a dilute oxygen stream (1\% of $\mathrm{O}_{2}$ in the inert gas) $\{28,41\}$. While this is legitimate when one is concerned only with the shape and internal structure of the metal NPs, it is not clear how much surface state dependent properties such as dielectric properties, magnetism or sintering resistance are modified by this passivation treatment. To study the intrinsic properties of reduced Co metal, it would be preferable to maintain the surface in its native reduced state.

In this paper, the structure and properties of Co metal/multiwall CNT (Co/MWONT) hybrids is reported with different Co contents. As the MWCNTs internal geometry is used to template and to stabilize Co magnetic NPs below the $10 \mathrm{~nm}$ range (something that is particularly challenging for $3 d$ metals), a precise control of the MWCNTs properties is essential. To that respect, we used MWCNTS of $3-4 \mathrm{~nm}$ internal average diameter and of $4-6 \mathrm{~nm}$ average wall thickness carefully synthesized and characterized by some of us in previous works $[42,43]$. The reduction of the precursors is followed by temperature programmed reduction (TPR) and in situ synchrotron X-ray diffraction (XRD). High-Resolution Transmission Electron Micros copy (HRTEM), and state-of-the-art ${ }^{59} \mathrm{Co}$ internal field nuclear mag netic resonance (IF-NMR) [44] were combined to probe the shape, structure and magnetism of the Cobalt phase after reduction. IF-NMR is particularly valuable as it reveals quantitatively the different Co metal magnetic NP structures and provides size estimations without exposure to oxygen, information not available by other methods $[41,45-51]$. In this way, we demonstrate that $\mathrm{Co}(0)$ phase in the nanometer range can be cast into the CNTs as ferromagnetic NPs of high aspect ratios or short nanowires. We further show that in situ polymerization of polyethylene on $\mathrm{Co}$ / MWCNT results in a composite with improved dielectric properties (Fig. 1).

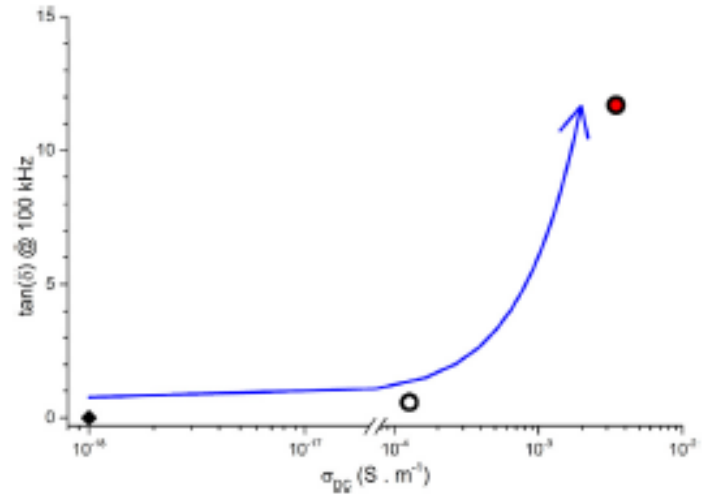

Fig. 1. Comparisan of properties of MWONI polymer amparites in view of enhylad ahsorption properties The arrow points the improvement toward a high conductivity and high lass material at the largst possible baldwidth (here $100 \mathrm{kHz}$ ). Blad dia mand: typical value for pol yethylene; empty dirde: MWCNI palyettylere omparite, this study; filled dicle: ColMWONI polyethylene omposit, this study. The dat: carrespond to the samples disassed liter in fig. 9 . (A mlour version of this figure can be viewed online)

\section{Experimental section}

\subsection{Synthesis of MWONTs and functionalization}

MWONTs were synthesized by ethylene decomposition over bimetallic $\mathrm{Fe}-\mathrm{Co}$ catalysts at $680^{\circ} \mathrm{C}$ Conditions were chosen according to ref. [43,52] to target an internal diameter of 3-4 nm and a wall thickness of $4-6 \mathrm{~nm}$. These characteristics were controlled by statistical analysis of HRTEM images. The Nitrogen BET surface area, measured on the ASAP-2400 Micromeritics instrument, was $305 \mathrm{~m}^{2} / \mathrm{g}$. Carbon nanotube pre-treatment was performed by reflux of $1-2 \mathrm{~g}$ in an excess of concentrated nitric acid during $90 \mathrm{~min}$. The consequence of this treatment has been evaluated, including by DTA/TGA, in a previous publication [42]. It resulted in the formation of about 0.8 carboxylic groups per $1 \mathrm{~nm}$, while the surface area decreased slightly to $300 \mathrm{~m}^{2} / \mathrm{g}$.

\subsection{Co/MWONT hybrids preparution}

Co-containing samples were prepared by incipient wetness impregnation of MWCNTs with aqua solutions of cobalt nitrate [53]. After impregnation for $2 \mathrm{~h}$, the sample precursors were dried at $110^{\circ} \mathrm{C}$ for $12 \mathrm{~h}$ followed by calcination at $350^{\circ} \mathrm{C}$ for $4 \mathrm{~h}$ under an argon atmosphere. They were then reduced in a stream of pure hydrogen $(40 \mathrm{ml} / \mathrm{min})$ at $350^{\circ} \mathrm{C}$ for $3 \mathrm{~h}$ with a heating rate of $2{ }^{\circ} \mathrm{C}$ l min. Varying the concentration of the cobalt nitrate solutions, samples of $3.5,7.5,11.7$ and $14.5 \%$ Co bading (in weight) were obtained. This was controlled by X-ray fluorescence (XRF) using a sequential spectrometer ARL. Perform'X with a Rh anode X-ray tube. The prepared samples were denoted as $x \% \mathrm{Co} / \mathrm{MWONT}$, the number $x$ standing for the cobalt load in weight $\%$. The completeness of the reduction process was verified by temperature programmed reduction (TPR) (Fig. S1). Reduced samples were transferred into NMR ampoules, which were sealed without contact with air immediately after the reduction procedure.

The in situ polymerization of polyethylene on $\mathrm{Co} / \mathrm{MWCNT}$ was carried out as follows. Solvents were purified but reactants were used as received from Sigma Aldrich. Co/MWCNTs (1 g), previously sealed in a glass ampoule, were suspended under an argon atmosphere in heptane containing Triisobutylaluminum $(0.4 \mathrm{mmol} / \mathrm{g} \mathrm{Co})$ MWCNT) and $\mathrm{TiCl}_{4}(0.35 \mathrm{mmol} / \mathrm{g} \mathrm{Co} / \mathrm{MWCNT})$. The suspension was 
dispersed by ultrasound and transferred under $\mathrm{Ar}$ atmosphere into a 1 L steel reactor for ethylene polymerization. During the polymerization, the ethylene pressure ( $3-5 \mathrm{~atm}$ ) and temperature $\left(40^{\circ} \mathrm{C}\right)$ were maintained constant. The reaction was carried out until the desired amount of polyethylene was obtained. After the synthesis, the Co/MWCNT polythylene composites were stored under air. It will be checked, as exposed below in the Results section, that polyethylene protects efficiently the Co from oxidation.

\section{In situ synchrotron $X$-ruy diffraction (XRD)}

The crystal phase trans formations of the cobalt phase during the reduction of impregnated MWCNT precursors were monitored in situ by XRD on a VEPP 3 Precision Diffractometry station at the Siberian Center of Synchrotron and Terahertz Radiation. The samples were placed in an XRK 900 X-ray reaction chamber (Anton Paar, Austria). Heating was performed from room temperature to $700^{\circ} \mathrm{C}$ at a speed of $10^{\circ} \mathrm{C} /$ min under a flow of diluted $\mathrm{H}_{2}\left(\mathrm{H}_{2}\right.$ rate of $150 \mathrm{ml} / \mathrm{sec}$ ). An intermediate stage at $350^{\circ} \mathrm{C}$ for $200 \mathrm{~min}$ was observed. The X ray patterns were recorded in near real time ( $60 \mathrm{~s}$ per frame) with an OD $3 \mathrm{M} 350$ position sensitive detector in a 26 range of $33^{\circ}-65^{\circ}$ with steps of $-0.01^{\circ}$ (operating wavelength, $0.1731 \mathrm{~nm}$ ), so as to capture the main reflections of $\mathrm{Co}, \mathrm{CO}_{3} \mathrm{O}_{4}$ and $\operatorname{CoO}$. The X-ray patterns were interpreted using the Topas full profile analysis program. The contribution of the baseline was eliminated by conducting additional experiments on the original nanotubes.

\section{High Resolution Trunsmission Electron Microscopy (HRTEM)}

Morphologies of the CNT supports and of the Co/MWONT hybrids were characterized using a JEOL JEM-2010 microscope operating at $200 \mathrm{kV}$ accelerating voltage which allows a nominal resolution of $1.4 \mathrm{~A}$. Sample specimens for TEM studies were prepared by dispersion of the powder in hexane in a glove box under Argon. The hexane suspension was removed from the box and a drop deposited onto a Micro-mesh copper grid and then quickly transferred to the TEM vacuum chamber where it evaporated. The total time of exposure of the hexane suspension to atmos phere was 20 s. The MWCNT mean diameters and Co partide size distributions were estimated from a statistical count of the nanotubes from several frames taken on different parts of the samples.

\section{5. ${ }^{59} \mathrm{Co}$ internal Field nuclear magnetic resonance (IF-NMR)}

All ${ }^{59} \mathrm{Co}$ IF-NMR experiments were carried out using a Bruker Avance NMR console without external magnetic field application, i.e outside of the NMR magnet, and at ambient temperature. A commercial broadband static low Q NMR probe head with tuning and matching capacitors was used. Although the measurements were not performed in situ, the samples were sealed on-line in the glass reactor used for reduction. Thus, during analysis, the samples did not evolve from the state they reached in the reactor, i.e, they were characterized in the same state of reduction and dispersion. The spectra were acquired using the spin-echo Fourier transform point by point method, described elsewhere [49]. The pulse train consisted of two identical pulses of 1 us duration with an interpulse delay of $8 \mu \mathrm{s}$. The number of transients varied from $1 \mathrm{k}$ to $8 \mathrm{k}$. The sequence repetition rate was $33 \mathrm{~Hz}$ due to the very short $T_{1}$ relaxation time of ferromagnetic cobalt. Low pulse powers were implemented ( $<10 \mathrm{~W}$ delivered at the radio-frequency coil) due to the high enhancement factor of metallic Co [54]. All Gaussian peak positions were determined from the "optimal" spectra (see Supporting Information for the definition of an "optimal" spectrum) and were in agreernent with previous literature results. Only line widths and line intensities were varied, the peak positions remaining fixed during the spectral decompositions. Small manual deviation from the fixed line positions within $0.2 \mathrm{MHz}$ were allowed to optimize the fit. The details of decomposition procedure can be found elsewhere [54].

\subsection{Complex dielectric penmittivity measurement}

The complex dielectric permittivity was measured as a function of frequency and temperature using a HP4284A precision LCR meter in the frequency range from $20 \mathrm{~Hz}$ to $1 \mathrm{MHz}$. The complex effective permittivity was calculated according to the Fresnel equation. All measurements above $1 \mathrm{MHz}$ were performed only at room temperature. The permittivity in the $10 \mathrm{MHz}-20 \mathrm{GHz}$ range was measured using a vector spectrum analyzer (E8363B Agilent Technologies) a coaxial waveguide, an irregular microstrip resonator, and set of rectangular cavity multimode resonators as measuring probes. The permittivity in $200-1100 \mathrm{GHz}$ frequency range was measured in a Mach-Zehnder interferometer using continuous radiation generated by backward-wave tubes. The data were normalized to insure continuity between the different frequency ranges.

\section{Results and discussion}

\subsection{Assessing reduction and sintering by in situ synchurotron XRD}

In situ synchrotron XRD reveals the processes occurring during the reduction| of the samples. The actual TPR program was mimicked but for a faster heating rate to $350{ }^{\circ} \mathrm{C}$ to allow for a limited available beam-time, as displayed as an inset of Fig. 2.

In Fig. 2, the reduction of the $7.5 \% \mathrm{Co} / \mathrm{MWCNT}$ sample is displayed. The Co phase in the precursor sample initially consisted of a mixture of $\mathrm{CoO}$ and $\mathrm{CO}_{3} \mathrm{O}_{4}$ oxides, $\mathrm{As}$ the temperature increased, the characteristic peaks of $\mathrm{CO}_{3} \mathrm{O}_{4}$ progressively disappeared. The growth of the $\mathrm{COO}$ (111) diffraction line revealed that the first step of $\mathrm{Co}_{3} \mathrm{O}_{4}$ reduction (from $\mathrm{CO}_{3} \mathrm{O}_{4}$ to $\mathrm{CoO}$ ) occurred. Around $320^{\circ} \mathrm{C}$ all reflections from the $\mathrm{Co}_{3} \mathrm{O}_{4}$ phase disappeared. Simultaneously, the $C^{\circ}(111)$ peak emerged. Clearly, at this temperature, the second stage of $\mathrm{Co}^{\circ}$ reduction (from $\mathrm{CoO}$ oxide to $\mathrm{Co}$ metal) had started and proceeded during the $350^{\circ} \mathrm{C}$ stage. An assessment of the size of the metal particles seen by XRD can be obtained from the breadth of the (111) Co diffraction line using the Scherrer approximation (the face centered cubic (fcr) (111) reflection is used as it is less influenced by stacking faults than the (200) one) [54]. The coherent domain size remained roughly constant at $7-8 \mathrm{~nm}$ during the $350^{\circ} \mathrm{C}$ reduction stage. Sintering was then probed by raising the temperature to $700^{\circ} \mathrm{C}$ Starting at $550^{\circ} \mathrm{C}$, the coherent domain size increased to reach almost $80 \mathrm{~nm}$ at the final temperature of $700^{\circ} \mathrm{C}$ Simultaneously, the Co metal reflections dramatically grew. This meant that due to sintering, more and more Co reached the minimum size to diffract coherently and implied that, in the $7.5 \% \mathrm{Co} /$ MWCNT sample after reduction at $350^{\circ} \mathrm{C}$ a significant number of Co NPs were small enough to escape XRD detection, i.e. their size was $5 \mathrm{~nm}$ at the very most. Despite their small sizes, these particles resisted sintering until $550^{\circ} \mathrm{C}$, that is close to the Tammann temperature of cobalt metal $\left(604^{\circ} \mathrm{C}\right)[55]$, suggesting a relatively strong metal support interaction between the MWCNT and the Co particles [56].

\subsection{Purticles morphology and localization by HRTEM}

HRTEM images of reduced $\mathrm{Co} / \mathrm{MWONT}$ s of different $\mathrm{Co}$ contents are shown in Fig. 3. The localization and size of the Co NP was clearly revealed and depended on the total Co loading. The $3.5 \%$ 


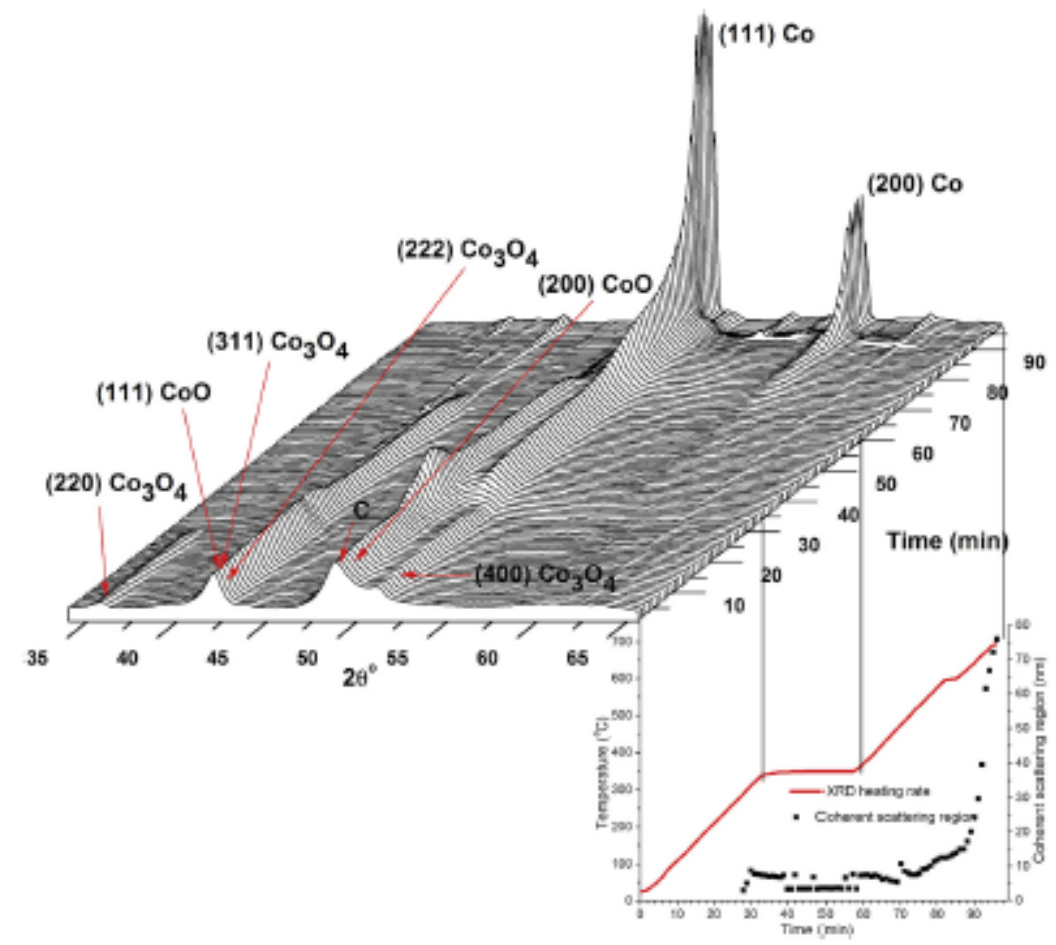

Fig. 2 Time-resolved XKD puterns of the cobalt phases impregnated in MWCNIs (75Y Co/MWONI) during reduction under diluzed hydrogen and tempenture sintering. The operting wavdength is $01731 \mathrm{~mm}$. The temperiture ramps and coherence size damairs derived from the Scherrer approwimation are also displayed. Co metal (PDF $15-806$ ), CoO (PDF 48-1719), $\operatorname{Con} \mathrm{O}_{4}$ (PDF 42-1467), and C (PDF 43-1104) indexation are shown. The successive reduction of steps of the cobalt spinel ints cobalt metal were evidenced but anly parbicles with wherent damin sizes above $5 \mathrm{~nm}$ are vis ible by XRD. Reduction, complete after the $350^{\circ} \mathrm{C}$ stage, was fal lowed by zmperitur sintering up to $700{ }^{\circ} \mathrm{C}$ Sinzering, as revealed by the increase of the wherest damain size, occurred anly after shout $550^{\circ} \mathrm{C}$ ( A clour version of this figure can be viewed anline)

sample exhibited only small Co particles inside the CNT channels while, at higher loading a second population of larger sizes appeared outside of the MWONTs.

The presence of Co NPs inside the MWONTsthusforming a true $\mathrm{Co}$ MWONT hybrid was a direct consequence of the nitric acid pretreatment whose effect could be visualized by HRTEM (Fig. S2) Despite, the fact that the nanotubes were closed at their ends, the treatment with nitric acid opened pores within the walls. Consequently, the Co ions could diffuseor be driven inside the tubes during impregnation and drying. Alternatively, the tip of the MWONTs could have been opened during the nitric acid treatment and closed during the reduction step. In between, during impregnation, the penetration of Co ions would have filled the inner space [38]. The most striking feature from Fig. 3 was that the first population, constrained by the internal dimensions of the nanotubes, was relatively narrow with a constant number average diameter of $3.6-4.0 \mathrm{~nm}$ and a standard deviation of $1 \mathrm{~nm}$, well in line with the internal nanotube diameter of $4 \mathrm{~nm}$ Furthermore, the localization of the small NPs population inside the MWONT and the resulting diffusion limitation might explain the resistance to sintering observed by XRD for the smal particles in the $7.5 \% \mathrm{Co} / \mathrm{MWCNT}$ hybrid.

As the Co loading increased, the inside population remained constant (Fig. 3) but the size distribution of the outside population increased, widened, and shifted toward higher values reaching a number average of about $21 \mathrm{~nm}$ at $14.5 \%$ loading. Analysis of the electron diffraction patterns of selected nanoparticles shown in Fig. 4 revealed that, in apparent contradiction with TPR results (Fig. S1) the Co phase present in the HRTEM chamber was partially oxidized. The large particles outside of the tubes had a Co-CoO core-shell structure with a shell thickness of $-2-3 \mathrm{~nm}$. Consistently, the small particles inside the tubes, being of diameters of less than twice the oxidized shell thickness, were essentially fully axidized. The discrepancy between the TPR, showing unambiguously that the samples were fully reduced, and electron diffraction data, showing the partial oxidation of the samples analyzed in the HRTEM chamber, likely resulted from a well-known limitation of HRTEM: despite the protection provided by the glove box and then suspension in hexane, the standard sample preparation inevitably resulted in some fractional exposure to air. Nevertheless, this did not alter the validity of the conclusions regarding the particle sizes and bcalization obtained by HRTEM. Actually, this incidental oxidation revealed that the Co NPs inside the MWCNTs were not particularly protected from oxidation. This behavior contrasted with recent observations by Badziz et al. [28] concerning dusters $(50 \pm 5 \mathrm{~nm})$ of Co NPs of similar sizes $(5 \mathrm{~nm})$ but confined inside non-porous MWCNTs with a wall thickness an order of magnitude larger (about $20 \mathrm{~nm}$ ), for which an extremely high resistance to oxidation was reported.

\section{Particles sizes, shapes and structures by $\mathbb{F}-N M R$}

Small particles escape XRD detection, and, as exemplified above, HRTEM is difficult to perform without a minimum level of oxidation. Taking advantage of the magnetic properties of Cobalt metal, these measurements can thus be usefully complemented by ${ }^{59} \mathrm{Co}$ IF-NMR [57]. Before even analyzing the ${ }^{39} \mathrm{Co}$ IF-NMR spectra, the 

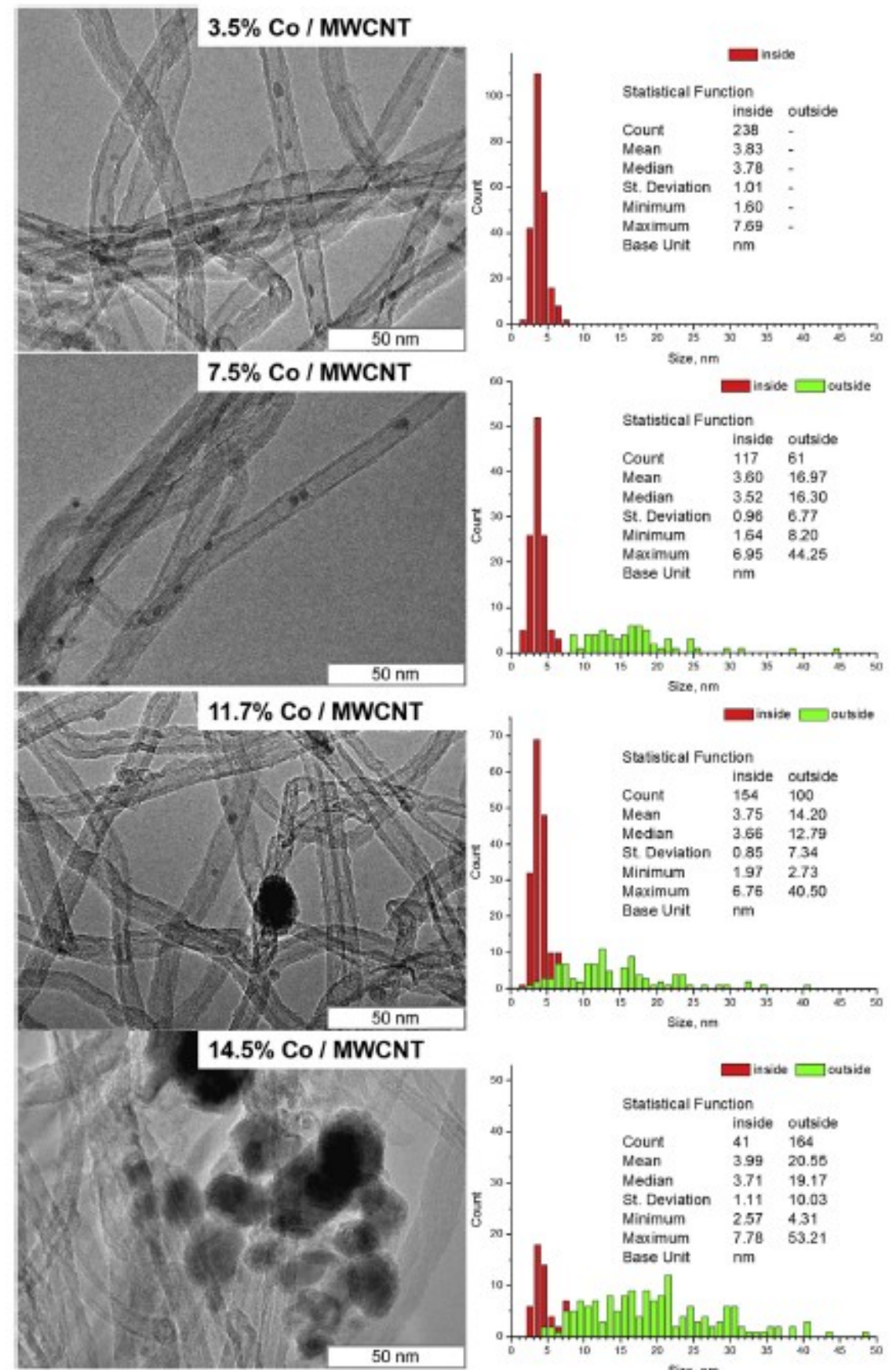

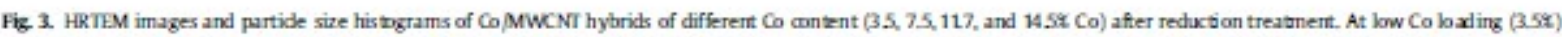
partides were only presert within the rumotube dunnels; their size histogram (in red) was very sharp and centered below 4 nm, that is with lateral eaters ions dezermined by the

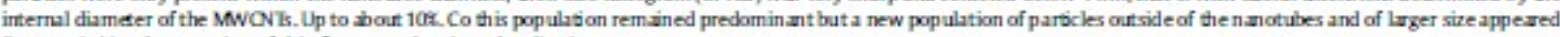
(in green), (A colour version of this figure can be viewed anline.)

fact that all samples provided a strong ferromagnetic signal was in itself very informative (Fig. 5). First, it demonstrated that the oxidation observed by HRTEM was indeed mostly an artefact and that a significant part, if not all, of the cobalt was indeed metallic in the pristine samples since it is the only one that can exhibit ferromagnetism. 


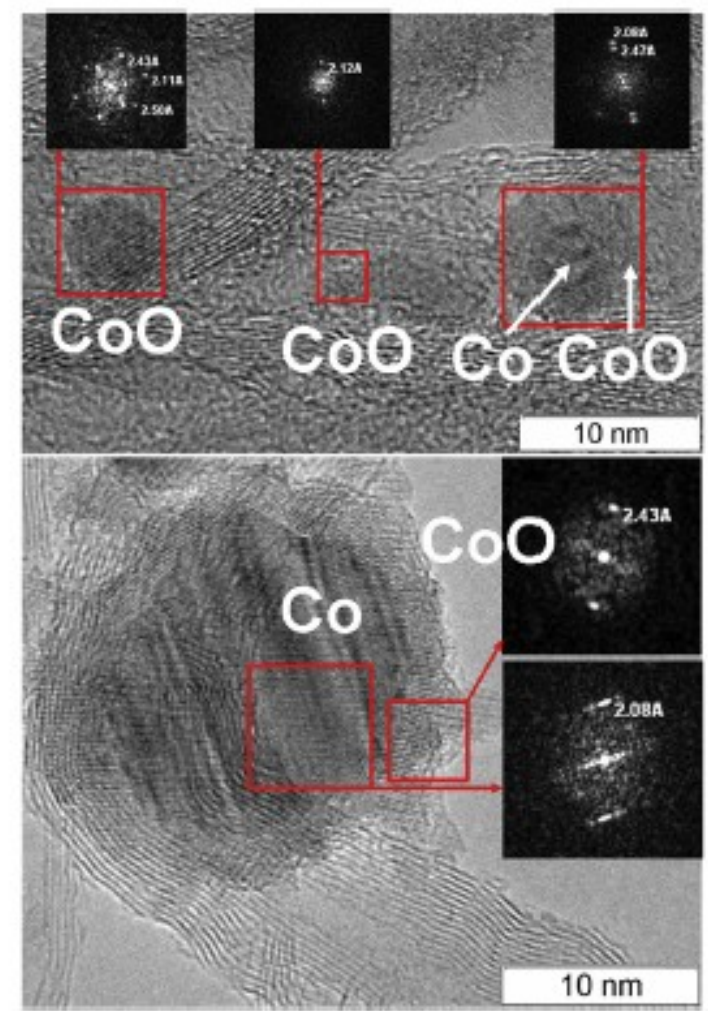

Fig 4. HRTEM images of 75\% (above) and 11.7x (bdow) Co/MWCNI hybricts after reducing treatment with eledron diffraction paterns. The particles of thesmall inside populabon appered fully widized while the larger oustide ones had a Co-CoO core. shell structures (A calour version of this figure carl be viewed on line)

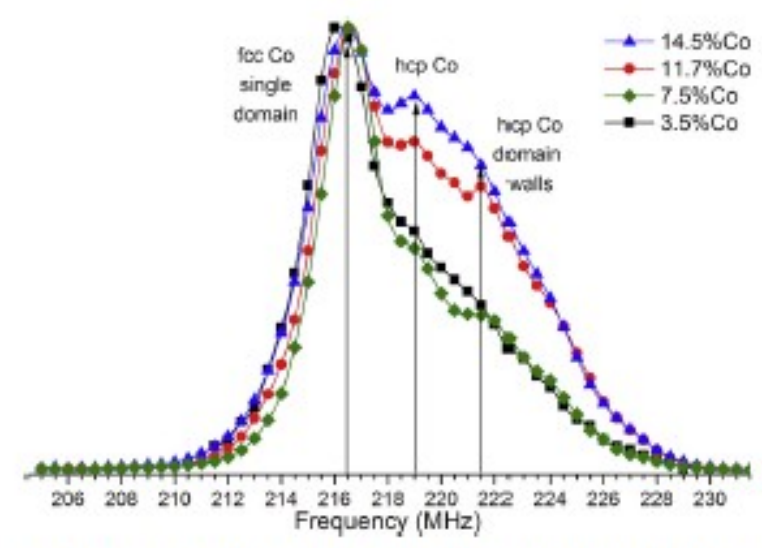

Fig. 5. Optimal ${ }^{\text {Na }}$ Co If-NMR spectra of all Co MWCNT hybrics $(3.5,75,112,14.5 \% \mathrm{Co})$ after reduction. Spectra are narmalized to maximum intensity (se Fig. 7 for qualio tative analysis). No contribution from multi damain fec partides ould be sen at $213 \mathrm{MHz}$ proving that no fix purbicles exceeded the critical domain size $I$ room temperisure ( $50-70 \mathrm{~mm} x$ the mast). For the resonances atributed to the hq system, a contribution from damain walk occurred des pite thesmall sine seen by HRTEM

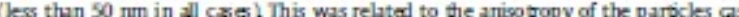
inside carbon nanotube chaminds. (A colour version of this figure can be viewed online.)
Furthermore, for small partides, the occurrence of a ferromagnetic behavior at room temperature is a signature of a significant aspect ratio. According to ref. [58], the blocking temperature $T_{B}$ for the superpara- to ferro-magnetic transition is given by

$$
T_{B}=\frac{1}{k_{B} \ln \left(\tau_{m} / \tau_{0}\right)} V K_{e f},
$$

where $V$ is the particle volume; $\tau_{m}$ is the time of the experimental measurements $\left(10-20 \mu s\right.$ in our case); $\tau_{0}$ is the characteristic relaxation time, in the range of $10^{-9}-10^{-11} \mathrm{~s}$; and $K_{\mathrm{e} f}$ is the magnetic anisotropy which results not only from magnetocrystalline anisotropy but also in part from shape anisotropy. For spherical Co particles, $K_{\mathrm{ef}}=5 \times 10^{6} \mathrm{erg} \cdot \mathrm{cm}^{-3}$, a value leading to a critical volume of $1.2 \times 10^{2} \mathrm{~nm}^{3}$ at room temperature, that is to a diameter of about $5 \mathrm{~nm}$. For the $3.5 \% \mathrm{Co} / \mathrm{MWONT}$ sample, the observation of a ferromagnetic behavior for particles that are all of equivalent diameter inferior to $8 \mathrm{~nm}$ established that $K_{e f}$ was significantly lower than in spherical partides, ie, that the Cobalt particles had significant anisotropy caused by the interaction with MWONTs [59]. Indeed, as shown in Fig. 6 (and Fig. S2), inside the MWCNTs, oblong particles and even nanowires could be detected by HRTEM

A deeper understanding could be obtained by analyzing the spectral response of the cobalt magnetic NPs. The room temperature corrected ${ }^{59} \mathrm{Co}$ IF-NMR spectrum of the reduced $11.7 \% \mathrm{Co}$ / MWONT samples is shown in Fig. 7 together with the variation of the enhancement factor with frequency. The optimal spectra of all the samples are represented in Fig. 5.

Further explanations concerning the notions of optimal and enhancement factorcorrections of IF-NMR spectra in ferromagnetic materials are provided in the Supporting Information. Briefly stated, the optimal spectra are obtained by varying the radiofrequency (rf) pulse power and recording for each sampled frequency the point of maximum intensity. The advantage of this representation is that it is independent of the acquisition conditions and is thus fully reproducible. Its disadvantage is that, because the rf field is enhanced differently by different magnetic structures, it is not directly quantitative. A correction by an enhancement factor is thus necessary to quantify the contributions of the different $C o$ ferromagnetic structures. Whatever the chosen representation, the contributions of face centered cubic (fcc) and hexagonal closed-packed (hcp) phases to a ${ }^{59} \mathrm{Co}$ IF-NMR spectrum are very different. The fcc structure being cubic, there is no difference between the resonance frequencies from magnetic domains and from domain walls. The resonances are thus sharp and an easy distinction can be made between the resonances of the foc multidomain $(213 \mathrm{MHz}$ ) and the one from the foc single-domain particles $(216.5 \mathrm{MHz})$ separated by the contribution of the demagnetization field to the local field. In contrast, in hep structures, the resonance is distributed over a wide rang e f frequencies to account for the contributions of $\mathrm{Co}$ in domain walls $(221.5 \mathrm{MHz})$, domain wall edges ( $214 \mathrm{MHz}$ ), and domains. The resonance frequency of the latter is poorly defined as it is broadened simultaneously by a large local field anisotropy and by a dispersion of local field values that is not predictable a priori since it depends on the particle shapes and sizes [44]. (Note that the resonances of $\mathrm{Co}$ in fcc structures with stacking faults cannot be distinguished from the ones in hcp structures as the local environment of $\mathrm{Co}$ are similar in both cases).

On this basis, the relative contribution of the fec and hep phases was simply obtained by subtracting the contribution of the two fec $213 \mathrm{MHz}$ and $216.5 \mathrm{MHz}$ resonances from the spectra (see an example in Fig. 6, the results of the decompositions being summarized in Table 1). The first observation is that the multi-domain $213 \mathrm{MHz}$ resonance was systematically absent in our samples. All the foc particles had thus a sing le ferromagnetic domain resonating 

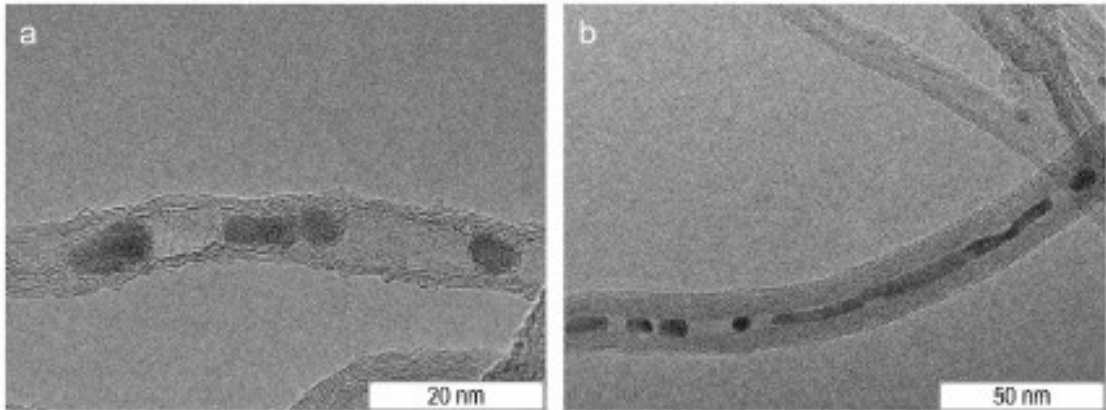

Fig. 6. (a) HRTEM image of 359 Ca/MWCNT showing oblong Co particles within the nanotubes; (b) HKIEM imse of 7.5\% Co/MwONT showing a Co partide of very high aspet rtia a Co nanowire inside a carbon nanoabe.

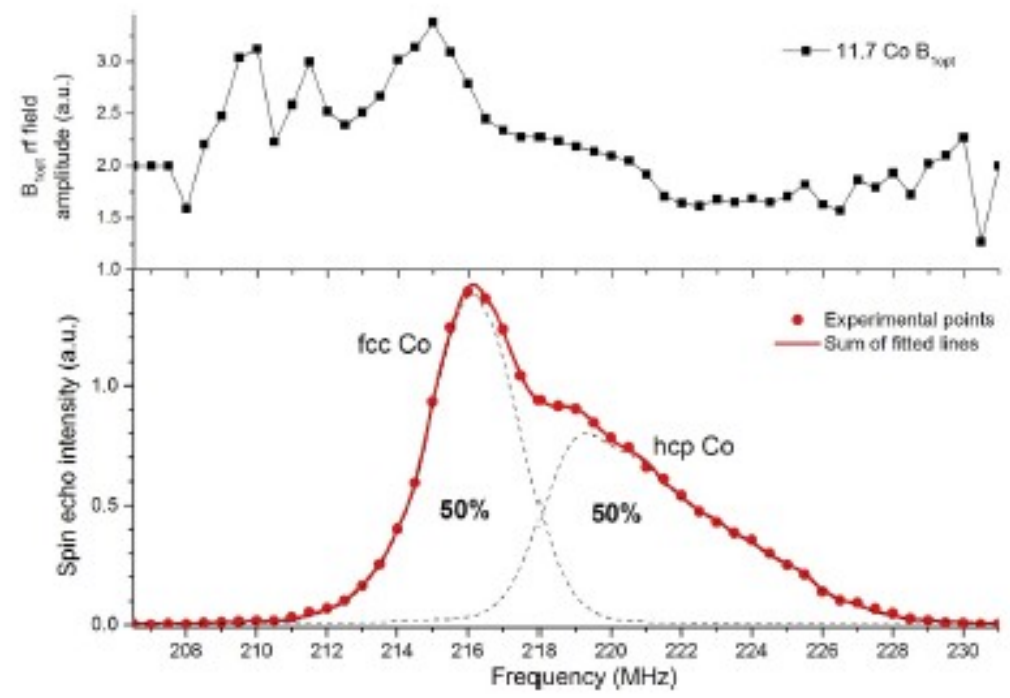

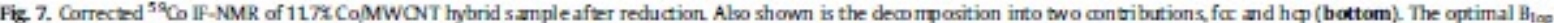

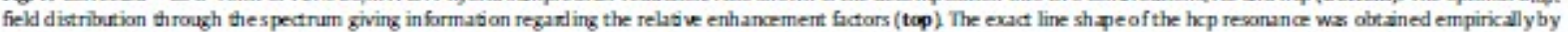
subtracting the fac Gussisn line shape. (A mlour version of this figure can be viewed anline.)

at $216.5 \mathrm{MHz}$, i.e. they were all smaller than the critical size of $\mathrm{Co}$ magnetic domains at room temperature namely $-50-70 \mathrm{~nm}[60]$ This was perfectly in line with the HRTEM images where no partides with a diameter larger than $50 \mathrm{~nm}$ were observed and very few reported above $30 \mathrm{~nm}$. The second observation was that the relative proportion of the hcp phase increased with the Co loading (Fig. 7 and Table 1). This could be related to the development of the outside population of partides of larger sizes evidenced by HRTEM. Kitakami et al. have evidenced that in small particles, the hightemperature foc structure is stabilized by the contribution of the surface free energy [61].

Consequently, as the partide sizes increased, the fcc phase was less stable and its proportion decreased with regards to the hop

\section{Table 1}

hep/foc ratio recalaulated from the fit of IF-NMR spectra. An example is provided in Fig. 6. The accuracy of the total fac (hcp) phase determination is $14 x$.

\begin{tabular}{lllll}
\hline Sample Co weight content & 3.59 & 7.59 & $11.7 x$ & 1.59 \\
\hline hep/fec ratio & $0.75 \pm 0.12$ & $0.58_{ \pm 0.10}$ & $1.00_{ \pm 0.16}$ & $1.17 \pm 0.19$ \\
\hline
\end{tabular}

structure. The growth of the hip resonance was especially marked around $221.5 \mathrm{MHz}$ (Fig. 5). Such a resonance frequency is typically attributed to Co metal at the center of domain walls in multi domain hop particles $[62,63]$. This line was barely resolved in the optimal spectrum representation of Fig. 5 but due to its high enhancement factor was clearly evidenced at low rf field intensity (Fig. S3). The development of magnetic domain walls, possibly not of the same nature as classical Bloch or Néd walk, for partides of effective diameters inferior to the theoretical critical magnetic domain size for spherical partides was further proof that particles of high aspect ratio formed. This $221.5 \mathrm{MHz}$ resonance was thus a signature of the bi-dimensional Co metal structures (nanowires) filling the MWCNTs observed in HRTEM (Fig. 6b).

In summary, we obtained hybrid structure made of cobalt metal nanoparticles within MWCNT. The particles have shapes with a diameter determined by the inner one of the MWCNT, namely circa $4 \mathrm{~nm}$. These particles were of hop and foc structures and exhibited ferromagnetism at room temperature despite their small sizes due to their strong anisotropy. For Co loading above $7.5 \%$, additional cobalt nanoparticles were found outside of the nanotubes. 


\subsection{Dielectric properties}

Potential applications of this type of hybrid materials relies on their magnetic, dielectric or conducting properties. We have shown that the Co NPs confer an unexpected ferromagnetism to the $\mathrm{Co} /$ MWONT hy brids due to their high shape anisotropy. We now focus on their dielectric permittivity since the magnetic Co particle content is too small to expect a significant change in magnetic permeability (as was verified in the $40 \mathrm{MHz}-250 \mathrm{MHz}$ range, data not shown). Pure Co/ MWONT hybrids are not protected from oxidation by air, and thus cannot be used as such However, their original properties can be conserved when included as filler in a polymer composite. The ideal candidate for utilization ascarrier matrixesis polyethylene (PE)due to its plasticity and low melting temperature. However, conventional techniques of compos ite synthesis (mechanical mixing, dissolution in a melted poly mer, etc.) are not appropriate when dealing with a highly pyrophoric material such as finely divided Co metal To overtome these difficulties, polymerization was performed in situdirectlyon $\mathrm{Co} /$ MWONT, as suggested eartier [64].

According to the IF-NMR spectrum in Fig. 8, the Co metal structure is indeed conserved during in situ polymerization. therefore structural aspects derived from Co/MWONT hybrids are valid for ternary (Co/MWONT) in PE composites.

The electrical response at room temperature of the MWCNT in PE composites with or without Co was in line with percolation theory and typical of a three dimensional conductive network above percolation threshold. The frequency dispersion of dielectric parameters in conductive (here the MWONT) and insulating (here the PE) composites has been extensively modelled [65]. In Fig. 9, the frequency dispersions of the conductivity

$\sigma=\ell^{\prime \prime} \omega$

of the dielectric constant relative to the vacuum permittivity ro

$\frac{\ell}{\varepsilon_{0}}$

and of the loss tangent

$\tan \delta=\frac{\ell^{\prime \prime}}{\ell^{\prime}}$

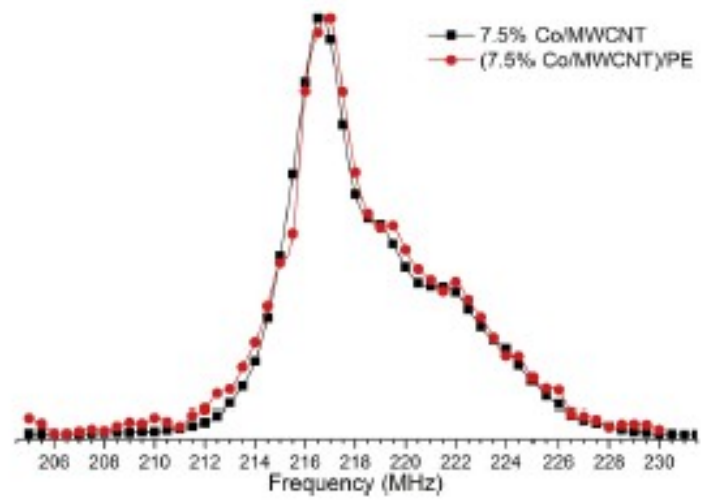

Fig. 8. 97. If-NMR spedra of 7.5Y Ca/MNONT hybrid sample after reduction (black squres) and in a PE ampos iz. The specta coinode within experimental errors proving that the Co is efficiently pro zected from axid sion in the PE. matrix, Note that the $75 \% \mathrm{Co}$ MWONI in PE amporit ontrin only $147 \%$ of CoMWONT, ie Co ontert ins ide the PI composit 2 is anly about $\sim 1$. (A colour version of this figurecan be viewed anline.)
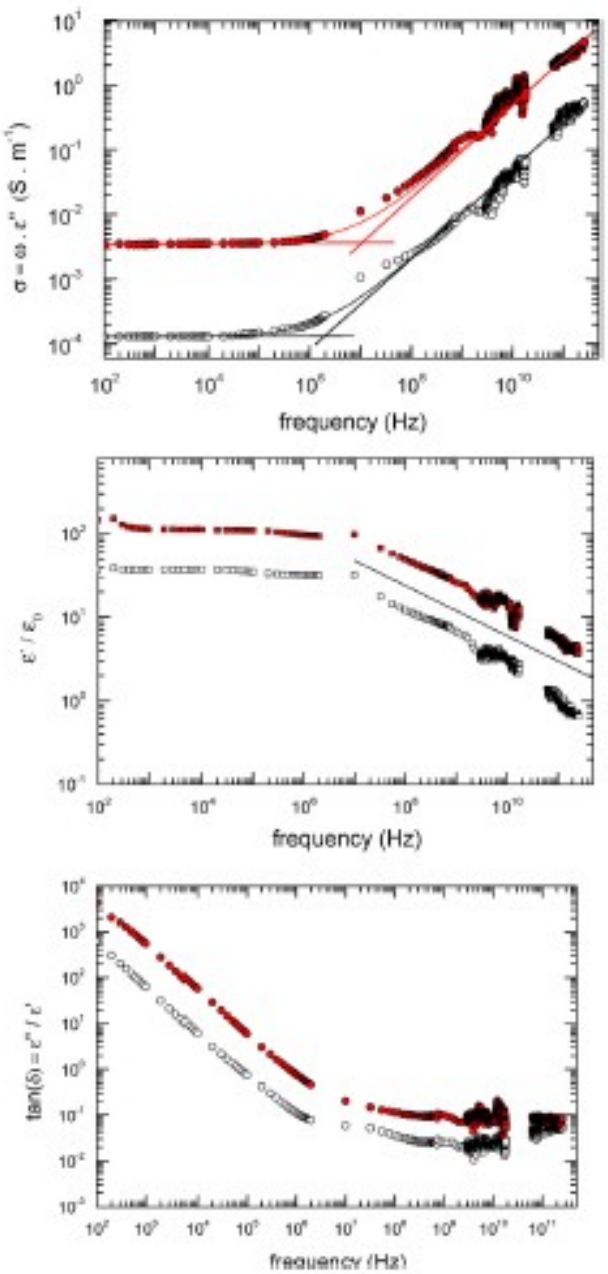

Fig 9. Room mperature frequency dispersion of dectrical conductivity relative dieledtric permittivity and loss tangent sample of similar characteris bic but with and without Co ranopurider. Full symbol, with Co: $13.6 \%$ of (7.5\% Co/MNONT) in PE. Empty symbols without Co: 100 t of MWONT in PE. Lines are drawn to show the power laws followed by the anductivity (exponent 07 ) and the dieledric anstant (exponest -0.3 ). Accordinghy the conductivity dita were fited with an Almand-West

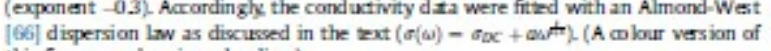
this figure can be viewed online.)

of the composites with and without Co are compared. Both samples exhibit the same behavior. Below a crossover frequency, the effective conductivity is constant. Above this crossover frequency, the conductivity increases with frequency while the dielectric constant decreases.

The conductivity is constant at low frequency as the contribution of the DC conductivity, namely the long-range motion of charge carriers, dominates. Beyond a crossover frequency, the effective conductivity and the dielectric constant follow power laws with exponents of about 0.7 and -0.3 , respectively. This behavior is thus very close to the prediction of models of 3D random distribution of complex resistors, 0.72 and -0.28 [67-69]. Accordingly, above percolation, the frequency and dielectric constant dispersion beyond the crossover frequency are given by the following scaling laws 
Table 2

$D C$ conductivity and crossever frequency between the $D C$ and $A C$ conductivity and corresponding estimation of the variation of the distance to percolation of the samples with and without 60 acording to eruations $(8)$ and $(9)$ and the $d \boldsymbol{x}$ for

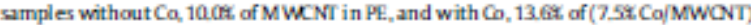
in $\mathrm{PE}$ as provided in Fig. \&.

\begin{tabular}{|c|c|c|c|}
\hline & Without Co & With Co & 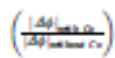 \\
\hline$\sigma_{\mathrm{sc}}\left(\mathrm{S} \mathrm{m}^{-1}\right)$ & $1.310^{-4}$ & $3410^{-4}$ & 5 \\
\hline$\omega_{c}(M H z)$ & 2 & 10 & 1.8 \\
\hline
\end{tabular}

$\sigma(\omega) \propto \omega \frac{s}{F+a}$

$\ell(\omega) \propto \omega \omega^{-\frac{1}{t+a}}$

$t \equiv 2$ and $s \equiv 0.8$

Interestingly, the value of the dielectric constant is higher for the sample containing $\mathrm{Co}$. This is probably related to the fact that the $D C$ conductivity of this sample is also higher by an order of magnitude in this sample. There is no direct explanation for this as the geometry of the conductive network is not expected to be significantly affected by Co loading of the MWONT. This can be appreciated by considering the scaling laws of the crossover frequency $\omega_{O}$ of the DC conductivity $\sigma_{D C}$, and of the static permittivity $\varepsilon_{s}$ with respect of the distance to the percolation threshold $\Delta \phi:$ [65].

$\omega t \propto|\Delta \phi|^{(t+s)}$

$\sigma_{D C}=\sigma(\omega \rightarrow 0) \propto|\Delta \phi|^{t}$

From that, it follows that if the difference in the dielectric properties where solely due to different percolation of the resistor networks, estimation of the ratio of the distance to percolation for both samples through the percolation frequencies or through the DC conductivities should be similar. Experimental estimates are reported in Table 2 from which it appears that the increase in DC conductivity was higher than what would be consistent with a difference in percolation everything remaining equal. In support of this conclusion, we have observed in a previous study of MWONT/ PE composites [64] that doubling the nanotube content inside PE composite from 10 to $20 \%$ does not drastically change the dielectric properties. It could thus be safely concluded that it was the presence of $\mathrm{Co}$ that was responsible for the enhanced conductivity. The respective contribution of inside and outside particles remains though to be clarified.

The conductivity of elongated conducting heterostructures is determined by the junction resistance at the contacts [70]. This means that the presence of Co was responsible for a significant decrease of the junction resistance between MWONTs. Enhanced permittivity upon $\mathrm{Co}$ loading of carbon nanotubes has been already reported in the literature albeit of lower extent but remains unexplained [35]. In any case, Co loading of the MWCNT resulted in PE composites with a conductivity increased by an order of magnitude. This property is combined with a loss tangent that remained above 10 up to the $100 \mathrm{kHz}$ range, as opposed to only up to the $1 \mathrm{kHz}$ range for the sample without $\mathrm{Co}$. As this was obtained with a minimal modification of the geometry of the percolating MWCNT network, this improvement both in terms of conductivity and absorption bandwidth was obtained without major modifications of the mechanical properties of the composite.

\section{Condusion}

Obtaining metal partides in the nanometer range can be experimentally very elaborate. Here, we showed that porous MWCNTs can act as templates to cast Co metal partides of elongated shapes following a simple incipient wetness procedure. Using MWCNTs of small internal diameter allowed the stabilization of particles with a diameter of less than $4 \mathrm{~nm}$ but with high aspect ratios. Small metallic particles are not expected to be ferromagnetic at room temperature but because of the tubular geometry into which they were cast, they had a high aspect ratio and magnetic anisotropy factor. This peculiar magnetic property meant that a true ferromagnetic Co/MWCNT nano-hybrid could be synthesized. Depending on the Co loading, particles with diameters an order of magnitude larger could also be deposited on the outside of the tubes. Quantification of each population was performed by HRTEM but this technique does not preserve the oxidation state and phase structure of the particles. On the contrary, IF-NMR provided an original mean to characterize the magnetic NPs in their fully reduced state. Based on the different resonances of ferromagnetic single domains and of domain walk, the absence of large particles and the high aspect ratio of the particles inside the MWCNTs were confirmed up to 7.5 wt\% Co loading. Furthermore, the relative amounts of fcc and hop crystalline phases could be quantified, an information which can be of high interest for catalysis [71] and batteries [12] applications and cannot be obtained by other methods.

The Co magnetic NPs were not protected from oxidation but synchrotron XRD showed that they resisted sintering up to $550^{\circ} \mathrm{C}$ This property is of high interest in catalysis. However, beyond this, the possibility to exploit simultaneously the original electrical transport properties of CNTs and the magnetism of Co NPs also opens the way to use the Co/MWCNT hybrid as a component for polymer composites with new electro-magnetic properties. Although the values of conductivity reached in the present study were not sufficient for effective applications [72], the conductivity was improved by an order of magnitude and the absorption bandwidth in low frequency range by almost two order of magnitude up to $100 \mathrm{kHz}$ Work is ongoing to understand the respective role of Co particles inside and outside the QNTs, the maximum Co intake inside the ONTs, and how to control the formation of magnetically coupled chains or of long nanowires so as to improve shielding properties in the microwave and terahertz range.

\section{Adknowledgements}

The samples preparation and parts of a part of their characterization were made possible by the financial support of the Russian Foundation for Basic Research via grant 16-32-60046 mol_a_dk (Mariya A. Kazakova). Olga B. Lapina and Andrey S. Andreev thank RAS Project V.44.1.17. A. Andreev was also supported in part by a PhD grant from the French Embassy in Moscow and by the Société des Amis de l'ESPCL The authors thank A. S. Lisitsyn from BIC SB RAS for the TPR analysis and discussion. The authors also thank Professor C. Mény for fruitful discussions regarding IF-NMR. Valentin I. Suslyaev, Evgeniy Yu. Korovin, and Victor A. Zhuravlev are also acknowledged for their help during dielectric measurements, as well as N.V. Semikolenova for Co/MWCNT-PE composite sample preparation. 


\section{References}

[1] A.H. Lu, EI Salahas, F. Schüth, Magnetic manopar tides: synthecis, protaction, functionalization, and application, Angew. Chem. Int. Ed 46 (2007) 1222-1244. http://dxdoiarg/10.1002 /anie 200602966.

[2] A. Alkharzadeh, M. Samiei, S Davaran, Magnetic nanopartides: preparation, physical properties and applications in biomediane, Nanoscale Res Lett. ? (2012) 144, http///dxdoiarg/10.1 186/1556-27 6X-7-144.

[3] QA. Pankhurst, I Comolly. S.K. Jones, I. Dobson, Applications of magnetic manopartides in biomedicine, J. Phys Appl. Phrys 36 (2003) R167-R181. http://dxdoiarg/10.1089/0022-3727/36/13/201.

[4] A. It , M. Shinkai. H Honda, T. Kobayz hi, Medical application of functional. ized magnetic nanoparticles, I. Biasci. Hiceng 100 (2005) 1-11, hitp:// dedaiarg/10.1263/jbb.100.1.

[5] f Gaa, H. Cu, B.Xu. Mul t functional magnetic nanoparticles; design, synthesis. and biomedical mplictions, Acc. Chem. Res 42 (2009) 1097-1107, http: bedoicorg $/ 10.1021 / 29000026$

[6] S. Bartling.C. Yin, L Barke, K. Oldenburg, H. Hartmann, V. von Oeynhausen, M. M. Pohl K. Houben EC. Tya, S. Seifert, P. Lievens K.H. Meiwes-Broer, S. Vajda, Pronounced size dependence in structure and morphology of gas phase produced, partally oxidized cobalt nanoparticles under catalytic reaction produced, partaly oxidized cobalt nanoparticles under catalytic reaction
conditions. ACS Nano 9 (2015) 5984-5998, http:/dxedoiarg/10.1021/ anditions $A C S$

[7] H. Zhang. C. Lancelat, W. Chu, f. Hong, A.Y. Khodakov, P.A. Chernavskii J. Zheng. D. Tang. The nature of cobalt species in carbon manotuhes and their catalytic performance in Fischer-Tropsch reaction, I Mater. Chem. 19 (2009) 9241-92 49, http://dxdoiarg/10.1039/6911355j.

[8] H. Xiang, MA.M. Motchelaha, M. Moyo, LL_Jewell, N.J Coville, Correlating the preparation and performance of cobalt catalysts supported an carbon nanktubes and carbon spheres in the Fischer-Tropsch synthesis. I Catal. 278 (2011) 26-40, http://dxdoiarg/10.1016/jijat 2010.11.010.

[9] S. Ientijo-Maza, R.P. Tan C. Carcia-Marcelot, T. Altantris, P.-F. Fazzini T. Hungria, B. Cormary, IR Gal lagher, JT, Miller, H. Martinez, S schrittwieser, I. Schotter, M. Respaud, S. Bak, G. Var Tendeloa, C. Gatel, K. Soulantica. Air and water-resistant noble mebl canted ferromagnetic whalt nanorods. $A C$ Nano 9 (2015) 2792-2804, http;//ded oi.arg/10.1021/m506709k

[10] J. Kim, Y. Pia, T. Hyeon, Multifunctional nanostructured materials for multimodal imaging, and simultaneous imaging and therapy. Chem. Soc. Rev. multimodal imaging, and simultanecus imaging and ther.
$38(2009) 372-390$, http://dxdoi.org/1 0.1039/[709893 A.

[11] Y. Xu, M. Mahmood, Z li, E. Dervishi. S. Trigwell, V.P. Zhrov, N. Ali, V. Saini A.R. Biris, D. lupu, D. Boldor, A.S. Biris, Cohalt nanoparticles coated with graphitic shells as localized radio frequency ahsorbers for cancer therapy. Nanotachnology 19 (2008) 435102, http:/dadoiorg/10.1088 p957-4484/19/ Nanotachni 435102 .

[12] C. Rosant, B. Avale, D. Larcher, L Dupont, A. Friboulet, J-M. Tarascon, Biosynthesis of $\mathrm{CO} 304$ electrode materials by peptide and phage engineering: comprehension and future, Energy Environ Sci 5 (2012) $9936-9943$, http: dxdoiorg/10.1039/c2ee22234e.

[13] J.Cahana, L. Monconduit, D. Larcher, M.R Palacin, Beyond intercal tion based Li-ion hatteries; the state of the art and challenges of electrode materials reacting through comver sion reactions, Adv. Mater. Deerf. Beach Ha 22 (2010) E170-E192, h ttp;//dcdoiorg/10.1002/adma. 201000717.

[14] T. Fukuma u. T. Fujigaya N. Nakashima, Devedopment of n-type cotaltocene. encapsulated car bon nanotuhes with remarkab le thermoelectric property, Sci Rep. 5 (2015) 7951, http://dedai.arg/10.1038/srep07951.

15] S. lijima, Helical microtubules of graphitic ca bon, Nature 354 (1991) 56-58, http://dxdaiarg /10.1038/35405600

[16] M. Monthioux, VI Kurnetsov, Who should be given the credit for the dis covery of carbon nanotubes? Carbon 44 (2006) 1621-1623, http: //dxcdaingrg/ 10.1016/jarbon 2006.03.019

[17] A. Peigney, C. Larent E. Flahait, R.R. Bxa, A. Rousset Specificsurface area of carbon nanotubes and bundles of carbon nanotubes, Carbon 39 (2001)

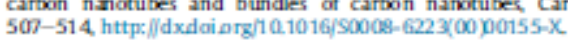

[18] S. Chakrahorty. I Chattopadhyay. H. Peng, Z Chen A. Mukherjee, R.S. Arvidson, R.H. Hauge, W.E Billups, Surface area measurement of funo tionalized single-walled cabon manotuher, J. Phys. Chem. B 110 (2006) $24812-24815$, http://dxdaiarg/ 10.1021 jp $0605044 \mathrm{u}$

[19] A.E Aliev, M.H. Lima, E.M. Silverman, R.H. Haug hman, Thermal conductivity of multi-wal led carbon nanotube sheets: raliation losses and quenching of phonon moder, Nanotechnology 21 (2010) 035709, http://dxdailarg/10.1088 $0957-4484 / 21 / 3 / 035709$

[20] DJ. Yang Q Zhang. G. Chen, S.F. Yoon, J. Ahr, SG. Wang, Q. Zhou, Q Wang. J0. Li. Thermal conductivity of multiwalled carbon nanotubes, Ptrys Rev. B 6 (2002) 165440, http://dx doiarg/10.1103/PhyskevB 66.165440.

[21] R. Prasher, Thermal boundary resistance and thermal onductivity of multi. walled carbon manotuhes. Phys Rev. B 77 (2008) 075424, http://dxdai.prs/ 10.1103/PhysRevil.77.075.424

[22] C.M. Chang. Y-L liu. Electrical conductivity enhancement of polymer/multiwalled carbon ranotube (MWONT) composites by thermally-induced defunctionalization of MWCNIs, ACS Appl. M

[23] EJ. R.2, K.H. An, K.. Kim, SY. Jeang. Y.. lee, Anisotropic electrical conduo tivity of MWONTPAN manofiber paper, Chem. Phys. Lett 413 (2005) 188-193. http://dxdaiorg/10.101 6/j.qplett2005.07.061.
[24] A.V. Eletskii, A.A. Knizhnik, B.V. Potapkin, JM. Kenny, Electrical characteristics of carbon nanotube-doped composites, Phys. Utpekhi 58 (2015) 209-251. http://dedaiarg/103367/UFNe 0185201503 a0225.

[25] JN.Coleman, U Khan, W. . Blau, YK. Gunka, Smal but strong: a review of the mechanical properties of carbon nanotube-polymer composites, Carbon 44

[26] B. Arash, Q. Wanz V.K. Varadan. Mecharical proper ties of carbon nanotube/ polymer comparites, Sai. Rep. 4 (2014) 6479, http://dxdoiarg/10.1039/ srep06479.

[27] R.S. Ruoff, D. Qian, W.K. Liu, Mechanical properties of carbon nanotubes: theoretical predictions and experimental measur ennents, Comptes Rendus Phys 4 (2003) 993-1008, http://dxdoiarg/101016/jerhy.200308.001.

[28] W. Basiz, 1. Forea, S. Moldovan, V. Papaefthimiou, S. Zafeiratoқ, S BeginColin, D. Begin, O. Ersen, C. Pham-Hun, Microscapy imestigations of the microstructural change and thermal response of cotalt hased nanoparticles
confined irside a carbon nanotube medium. J. Mater Chem. A 3 (2015) 11203-11214, http://dxdoiarg/10.1039/CSTA00283D.

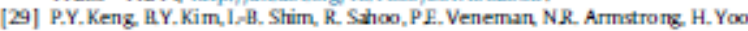
IE. Penherton, MM. Bull, If Griebel, ELL Ratcliff, K.G. Nebesny. I. Pyur, Colloidal polymerization of polymer-coated ferromagnetic nuopartides into cohalt waide nanowires, ACS Nano 3 (2009) 3143-3157, http: //dxdaiarz $10.1021 / \mathrm{mn} 900483 \mathrm{w}$.

[30] LV. Lutsev, NE. Kazantseva, LA. Tdımutin, NG. Ryvkina, YE Kalinin, A.V. Sitrikoff, Dielectric and magnetic lasses of microwave electromagnetic radiation in granular structures with ferromagnetic nanoparticles, J. Phys. Condens MAter 15 (2003) 3065-3681, http://dedoiorg/10.1088/0953-8984/ $15 / 22 / 302$.

[31] LV. Lutsev, Spin excitations in gramular structures with fer romagnetic nanopartides, Phys Solid State 44 (2002) 102-110, http://dxdoiarg/10.1134/ 1.1434594.

[32] P.M.F. Costa J. Slasn, T. Ruther ford, M.L. Green, Encapsulation of Rexoy clusters within sing le-walled carbon nanotuhes and their in tubulo reduction and sintering to re metal. Chem. Mater. 17 (2005) 6579-6582 http:// dxdais rg/10.1021/cm0510209

[33] I Martin-fabiani, M-C.Garda-Gutierrez, D.R. Rued2, A. Linares, H. Hernandez, T.A. Ezquerra, M. Reynold, Gystallization under ane-dimersional confine ment in aluminu nanopores of poly(trimethylene terephthalate) and its composites with single wall carbon nanotubes, ACS Appl Mater. Interfaces 5 (2013) 5324-5329, http://dxdaiorg/10.1021/am401194p.

[34] W. Basziz, S. Begin-Calin BP. Pichon, L Horea, Q Ersen, S. Zfeirator, R. Barbosa, D. Begin, C. Pham-Huu, High-density monodispersed cobal nanopartides filled into multiwalled crabon nanotubes Chem. Mater. 24 (2012) 1549-1551, http://dxedai. arg/10.1021/cm300293h.

[35] H. Lin, H. Zhu H. Cua L Yu, Microwave-ahsorbing properties of Co-filled carbon manotuhes Mater. Res Bull. 43 (2008) 2697-2702, http: //dx doior 8 10.101 6/j-materres bull.2007.10.016.

[36] K.V. Elumeeva, VI Kurnetsov, A.V. kscherka R. Smajda. M. Spina. L. Forro, A. Magrez, Reinforcement of CVD grown multi-walled carbon nanotuhes thy high temperature annealing. AIP Adv. 3 (2013) 112101, http: //dxdaiarg! high temperature
$10.1063 / 1.4829272$

[37] S.C. Tsang, Y.K. Ghen, P.JF. Harris, M..H. Green, A simple chemical method of operiing and filling carbon nanotuber, Nature 372 (1994) 159-162, http:// dxdaierg/10.1038/37215900.

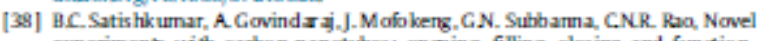
experiments with carbon nanotubes: opening, filling, closing and function alizing nanotubes, f Phys. B At Mol Opt. Phys 29 (1996) 4925-4934, http:// dxdaing/10.1088/0953-4075/29/21/006.

[39] N.Fischer, E van Steen, M. Claeys. Preparation of supported mano-sized cohalt wide and far cobalt crystallites, Cxal. Today 171 (2011) 174-179, http:/ dxdaing/10.1016/j.cattod 2011.03018.

[40] Y]. Wan, JL [j, DH. Chen, Kinetic characterization of the reduction of silica supported cobalt catalysts, Therm. Anal Calorim 90 (2007) 415-419, http: /f dxdaiorg/10.1007/s10973-006-7901-y.

[41] B. de Tymowski Y. Liu, C. Meny, C. Lefevre, D. Begin, P. Nguyen, C. Pham, D. Edouard, F. Luck C. Pham-Huu, Co-Ru/SiC impregrated with ethanol $\mathbf{x}$ an effectivecatal yst for the Fischer-Tropsch synthesis, Appil.Catal Ce

[42] L Maxvv, V.L Kursetsov, LA. Simonova, A. Stadnichenka, A.V. Is hichenloo, A.L Romanenko, E.N. Tkxhev, OH Anikeva Oxidation behavior of multiwall carbon nanotuhes with different diameters and morphology. Appl. Surf Sci. 258 (2012) 6272-6280, http: //do doiarg/10.101 6/japsux 201203021.

[43] V. (RU) Kursetsov A.N. (RU) Usoltseva Method of producing fine-grained supported catalysts and synthesis of carbon nanotuher. Patent RU 2373995. 2009

[44] AS. Andreev, J-B. d'Epinose de Lacillerie, OB. Lapina, A. Gerashenko, Thermal stabil lity and hop-foc alotropic trasformation in supported Co metal cxalysts probed near operando by ferromagnetic NMR. Plys. Chem. Chem. Phys 17 (2015) 14598-14604, http://dx doi arg/10.1039/C4CP05327C.

[45] Y. Liu, f. lua, M. Girleanu, O. Ersen, C. Phan-Huu, C Meny. Efficient hierar. chically structured composites containing whalt catalyst for clean synthetic fuel production from Fischer-Tropsch synthesis, f Catal. 318 (2014) 179-192, http://docdoi.arg/10.1016/j.jat.2014.08.006.

[46] Y. Liu, B. de Tymowski, F. Vigneron, I. Florea, Q Ersen, C. Mény. P. Nguyen, cobalt catalyst for Fischer-Tropsch synthesis ACS Catal 3 (2013) 393-404. 
http: //dx doiarg/10.1021/cs300729p.

(47) Y. liu, I. Florea Q. Ersen, C. Pham-Huu, C. Merry, Silican carbide coatod with TiO2 with enhunced whalt active phuse dispersion for Fischer-Tropsch synthesis, Chem Commun 51 (2015) 145-148 http://dedoiarz/10.1039/ synthesis, Oh

(48) AS. Andreev, O.H Lapina, J-B. d Espinose de Lacaillerie, A A. Khassin, Effect of alumina modification on the structure of cobalt-containing Fischer-Tropsch synthesis catalysts according to internal-field 5960 NMR data. I Struct. Chem.

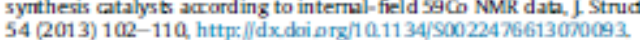

149] A. A. Andreev, S.F. Tikhov, A.N. Salanov, SV. Cherepanova, OB. Lapina, V.A. Bolotov, Y.Y. Tanahev, J-B d'Espinose de Lacallerie, V.A. Sadykov,

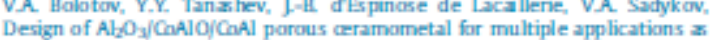

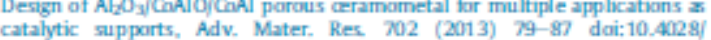
catalytic supports, Adv. Mather.

150] M. Beleci, I. Panagiotopoulos. S. Pal, S. Hariharan, D.Tsitrouli, G. Papavassi liou, D. Niarchos, N. Boukos, M. Fardis, V. Tzitzios, Decaration of carbon nanotube with $C O O$ and $C 0$ nanoparticles f. Nanomater 2011 (2011) 1-9, http:ll dxedoiarg/10.1 155/2011/320510.

[51] S.F. Tikhov, AS. Andreev, AN. Salanov, SV. Cherepanova, OB. Lapina, V.A. Sadykov, Y.Y. Tanashev, V.A. Bolotov, Ceramic matrix composites prepared from CaAl powders, I Mater. Sci. 51 (2016) 10487-10498, http: dxdoiarg/10.1007/s 10853-016-0268-y.

152] V.L. Kumietorv, SN. Bakova-Sirosh SI. Moseenkov, A.V. Ishchenka D.V. Krasnikov, M. Kazzakova, A.L Romanenka, EN. Tkachev, ED. Obraztsova, R.aman spectra for characterization of defective CVD multi-walled carbon

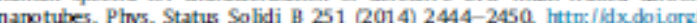
$10.1002 / \mathrm{prsh} 201451195$.

[53] M.A. Shuvaeva, GS. Litvak, V.A. Varnek, G.A. Bukhtiyarova, Preparation of supported iron-conta ining catalysts from a FeSo4 solution; the effect of the support Kinet Catal 50 (2009) $874-877$, http://dodailarg/10.1134/ sac023158409060123.

154] A.S. Andreev, O.H lapina S.V. Cherepanova, A new insight into cohalt metal powder internal field $\$ 96$ NMR spectra, Appl Magn Resan 45 (2014) powder internal field 5960 NMR spectra, Appl Magn

(55) J. Moulijn, A. van Diepen, F. Kapteijn, Catalyst deactivation: is it predictable? Appl. Catal Cen. 212 (2001) 3-16, http;//dbedaiarg/10.101 6/S0926-860x(00) $00042-5$.

156] JC. Matsubu, S. Zhang. I. DeRita NS. Marinkovic, JG. Chen, CW. Graham. X. Pan, P. Christopher, Adsarbate-mediated strong meta-support in teractions in oxide-supported Rh catalysts, Nx. Chem. (2016), http: / dxdoiarg/10.1038/nchem.2607.

57] Y. Liu J. Lua Y. Shin, S. Moldovan O. Ersen, A. Hébraud, G. Schlatter, C. Pham Huu C. Merny. Sampling the structure and chemical order in assemblies of ferromagnetic nanopartides by nuclear magnetic resonance Nat Commun 7 (2016) 11532, http://dedaiarg/10.1038/ncamms1 1532

(58) C de Juli in ferninder, influence of the tomperature dependence of anisotropy on the magnetic behsviar of nanopartides, Phys Rev. a 72 (2005)
054438, http://dxdaingrg/10.1103/Phys RevB.7205 4438.

[이 V. Skumryev, S. Stoyanov, Y. Zhang, G. Hadji panayiz, D. Givord, J. Nogues, Beating the saper paramagnetic limit with exchange bias, NIure $423(2003)$ 850-853, http://dxdaiorg/10.1038/nature01637.

[60] DL leslie-Pdedky, R.D. Keke, Magnetic properties of nanostructured mat: rials Chem

[61] 0. Kitakami H Sat, Y. Shimola, F. Sata, M. Tanakn, Sime effect on the cryst phase of cobalt fine partides. Phys Rev. B 56 (1997) 13849-13854, http:/

[62] M. Kawakami, T. Hihara, Y. Kai, The Cos9 nudear magnetic resanance in hexagonal cobalt. I Ptrys Soc Jpn. 33(1972) 1591-1598.

[63] H.P. Kunkel. CW. Searle, Experimental identification of domain-wall-centor and domain-wall-edge NMR resonanos in magnetically ordered materials, Phys. Rev. B 23 (1981) 65-68.

[64] M. Kazakova, V.I. Kurnetsor, N.V. Semikolenova, SI Mareerikov, D.V. Krasnikorv, M.A. Matska, A.V. Ishchenko, VA. Zakharov, A. Romanenkoo, OB. Anikeeva, EN. Thachev, VI. Sushyaev, V.A. Zhuraslev, K.V. Dorazkin. Comparative study of multiwa led carbon nanotube/polyethylene composite produced via different techriques, Phys Status Solici B 251 (2014) 2437-2443, http://dedoiorg/10.1002/pssh 201451194.

[6] A. Aharony, D. Stauffer, Introduction to Percolation Theory, Taylar \& Francis, 2003.

[66] DP. Almond, AR West, Impedance and modulus spectroscopy of "real" dispersive conductors, Solid State lan. 11 (1983) 57-64, http://dxdaing rg/ 10.101 6/0167-2738(83)90063-2

[6] P. Pötschke, SM. Dudkin, L Alig. Dielectric spectros apy on melt processed polycarbonate multiwalled carhon nanotuhe composites, Pohymer 44/2003)

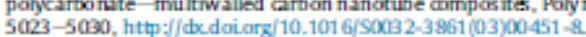

[Q8] D. Bergman Y. Imry, Gritical beh avio rof the complex dielectric constant near the perwlation threshold of a heterogeneous material. Phys. Rev. Lett 39 (1977) 1222

[ㅂ] f. Zhang, M. Mine, D. Zhu, M. Matua, Electrical and dielectric behaviars and their origins in the three-dimersional polyvinyl al cohol MWCNI camporites with knw percolation treshold Carbon 47 (2009) 1311-1320, http:/) dxdai arg/10.1016 [j,carbon .2009.01.014.

[70] S.I White, B.A. DiDorna, M. Mu. T.C. Lubers ky. K.L Winey. Sirnulations and electrical conductivity of percolated networks of finite rods with various degrees of 2xial alignment, Phys. Rev. B 79 (2009), http;//dxdoiarg/10.1 103 Phys Revi.7902 4301 .

[71] J-X. Liu, H_-Y. Su, D-P.Sun, B-Y. Zhang, W-X.Li, Gystallographic dependence of $C$ activation on cobalt catalysts: HCP versus RCC. I. Am. Chem. Soc. 13 (2013) 16284-16287, http://dxdaingr/10.1021/ja408521w.

[72] F. Oin, C. Brosseau, A review and analysis of microwave ahsorption in polymer comporites filled with carbonaceous partides. J. Appl. Phys 111 (2012) 061301, http://dxdoiorg/10.1063/13089435 